Article

\title{
Development of an Experimental Testbed for Research in Lithium-Ion Battery Management Systems
}

\author{
Nima Lotfi ${ }^{1}$, Poria Fajri ${ }^{2}$, Samuel Novosad ${ }^{2}$, Jack Savage ${ }^{2}$, Robert G. Landers ${ }^{1, *}$ \\ and Mehdi Ferdowsi ${ }^{2}$
}

1 Mechanical and Aerospace Engineering Department, Missouri University of Science and Technology, Rolla, MO 65401, USA; E-Mail: nlb6f@mst.edu

2 Electrical and Computer Engineering Department, Missouri University of Science and Technology, Rolla, MO 65401, USA; E-Mails: pfkr7@mst.edu (P.F.); slnd54@mst.edu (S.N.); jssgh6@mst.edu (J.S.); ferdowsi@mst.edu (M.F.)

* Author to whom correspondence should be addressed; E-Mail: landersr@mst.edu; Tel.: +1-573-341-4586; Fax: +1-573-341-6899.

Received: 19 August 2013; in revised form: 10 September 2013 / Accepted: 25 September 2013 / Published: 15 October 2013

\begin{abstract}
Advanced electrochemical batteries are becoming an integral part of a wide range of applications from household and commercial to smart grid, transportation, and aerospace applications. Among different battery technologies, lithium-ion (Li-ion) batteries are growing more and more popular due to their high energy density, high galvanic potential, low self-discharge, low weight, and the fact that they have almost no memory effect. However, one of the main obstacles facing the widespread commercialization of Li-ion batteries is the design of reliable battery management systems (BMSs). An efficient BMS ensures electrical safety during operation, while increasing battery lifetime, capacity and thermal stability. Despite the need for extensive research in this field, the majority of research conducted on Li-ion battery packs and BMS are proprietary works conducted by manufacturers. The available literature, however, provides either general descriptions or detailed analysis of individual components of the battery system, and ignores addressing details of the overall system development. This paper addresses the development of an experimental research testbed for studying Li-ion batteries and their BMS design. The testbed can be configured in a variety of cell and pack architectures, allowing for a wide range of BMS monitoring, diagnostics, and control technologies to be tested and analyzed. General considerations that should be taken into account while designing Li-ion battery systems are reviewed and different technologies and challenges commonly encountered in
\end{abstract}


Li-ion battery systems are investigated. This testbed facilitates future development of more practical and improved BMS technologies with the aim of increasing the safety, reliability, and efficiency of existing Li-ion battery systems. Experimental results of initial tests performed on the system are used to demonstrate some of the capabilities of the developed research testbed. To the authors' knowledge, this is the first work that addresses, at the same time, the practical battery system development issues along with the theoretical and technological challenges from cell to pack level.

Keywords: Li-ion batteries; experimental testbed; battery management system

\section{Introduction}

A battery is an energy storage device that can convert the chemical energy of its material into electrical energy. Lithium-ion (Li-ion) batteries were first introduced in 1976 [1], and subsequently commercialized in cell phones and laptops by the Sony Corporation in 1991 [2]. Li-ion batteries are usually composed of a carbon-made anode, a lithium ion conducting material electrolyte, and a cathode. There are a wide range of commercial cathode materials including $\mathrm{LiCoO}_{2}$ and $\mathrm{LiFePO}_{4}$, each of which has its own advantages and disadvantages. The chemical reactions occurring in a $\mathrm{LiFePO}_{4}$ battery during charge and discharge are:

$$
\begin{array}{ll}
\text { Cathode : } & \mathrm{LiFePO}_{4} \underset{\text { discharge }}{\stackrel{\text { charge }}{\rightleftarrows}} \mathrm{FePO}_{4}+\mathrm{Li}^{+}+\mathrm{e}^{-} \\
\text {Anode }: & \mathrm{Li}^{+}+\mathrm{e}^{-}+6 \mathrm{C} \underset{\text { discharge }}{\stackrel{\text { charge }}{\rightleftarrows}} \mathrm{LiC}_{6}
\end{array}
$$

Li-ion batteries were first employed in consumer electronics; however, at the onset of 21 st century, due to their advantages such as high energy density, low weight, low self-discharge and long life, they began to dominate energy storage in other fields as well. Other recent applications of Li-ion batteries include electric and hybrid electric vehicles, alternative energy systems such as wind and solar energy, and stationary energy storage. According to a recent study by [3], Li-ion batteries have been the dominant battery technology in electric and hybrid electric vehicles for over thirty years. They are projected to continue this dominance in transportation and other sectors. Figure 1 shows the distribution of different energy storage technologies in electric and hybrid electric vehicles.

In order to gain an insight about battery characteristics and investigate its performance, different tests need to be performed. These tests can be categorized as characterization, lifetime, reliability, and abuse tolerance tests [4]. Galvanostatic intermittent titration technique (GITT) [5], potentiostatic intermittent titration technique (PITT) [5], cyclic voltammetry (CV) [6], and impedance spectroscopy [6] are some of the commonly used characterization tests. Although these tests provide very useful detailed information about batteries, they typically address individual battery cell characteristics and require advanced and expensive test apparatuses. In order to overcome these issues, a number of tests have been devised to characterize battery cells and packs for transportation applications. A summary of the main international battery test standards is given in [4,7]. Although these 
tests are mainly designed for transportation applications, a majority of them, such as capacity and hybrid pulse power characterization (HPPC) tests [8], can be used for other Li-ion battery applications as well.

Figure 1. Distribution of different battery technologies in the transportation sector during the last 30 years [3].

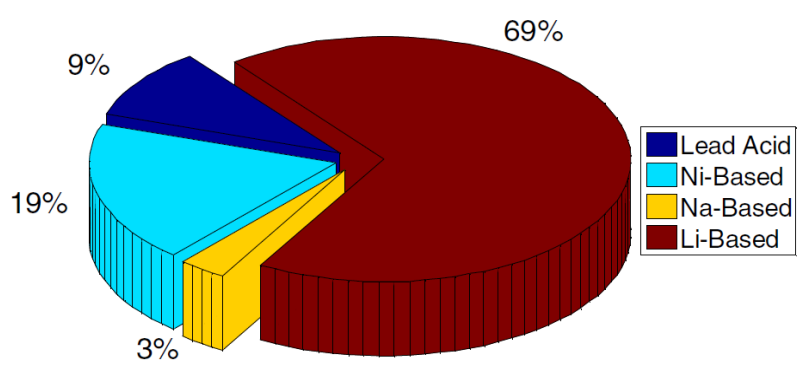

Mathematical modeling is used for battery performance analysis and prediction, design optimization, and management system design. There are numerous works in the literature on modeling Li-ion batteries. Doyle et al. [9] pioneered electrochemical battery modeling. These models predict the battery performance under different operating conditions and also provide insight into internal battery phenomena. Since Doyle et al.'s seminal work [9], different research groups have worked on model order reduction for these electrochemical models with the goal of easing the computational effort [10,11]. Although successful, the time-consuming parameter identification process is still a major drawback for these models. On the other hand, equivalent-circuit models, in spite of their limited prediction capability, have been employed extensively due to their efficient online implementation and low computational burden. One of the most commonly-used equivalent-circuit models is the improved Thevenin circuit model proposed by [12]. Furthermore, Hu et al. [13] introduced and compared 12 common battery models for online implementation. In addition to capturing battery dynamics sufficiently for different operating conditions, it is also very easy to identify equivalent-circuit model parameters. There are different methods to identify model parameters. Some of the aforementioned characterization tests such as HPPC can be used for this purpose.

One of the crucial components of a Li-ion battery is its battery management system (BMS). The most trivial task of a BMS is gathering and monitoring information about the battery operating conditions, namely, voltage, current, and temperature. For high voltage and current applications, multiple battery cells need to be connected together, in series and/or parallel, in order to meet the application requirements. In multiple battery configurations, balancing the battery cells is another responsibility of the BMS. More importantly, the BMS should be able to maintain a safe and reliable operation for the battery by controlling its operating voltage, current, and temperature. Finally, based on the battery measureable signals, and typically a battery model, the BMS needs to be able to estimate unmeasurable battery states such as state of charge (SOC) and state of health ( $\mathrm{SOH}$ ). In summary, BMS functionalities include measurement and monitoring, cell balancing, thermal and electrical protection, and state estimation. These functionalities are discussed in more detail below.

Measurement is undoubtedly one of the most important responsibilities of a BMS. Accurate voltage, current and temperature measurements are needed from battery characterization tests to BMS design. There are strict requirements for the accuracy and resolution of voltage and current sensors for Li-ion BMSs. Lu et al. [14] reviewed some of voltage measurement methods currently implemented in BMSs. 
Battery packs comprised of numerous cells require special attention from BMSs. Due to manufacturing variances, even matching battery cells have different internal characteristics. These differences cause the cells to charge and discharge at unequal rates. For that reason, the voltage across an entire series string of cells does not necessarily have a proportional voltage across each individual cell in that string. For example, a battery charger that only monitors the pack voltage will not fully charge certain cells and will subject other cells to overcharging. These issues can decrease the pack cycle life, cause a large loss in pack capacity over time, and result in safety hazards. To counteract these issues, a technique called cell balancing or charge equalization can be employed. This technique is implemented in a variety of ways; however, the concept for each method is similar. A balancing circuit maintains a uniform charge level among different cells by either dissipating excess energy from fully charged cells or by moving that excess energy to cells that are not fully charged.

Li-ion batteries have a typical operating temperature range of $-20{ }^{\circ} \mathrm{C}$ to $55^{\circ} \mathrm{C}$ for discharge and $0{ }^{\circ} \mathrm{C}$ to $45{ }^{\circ} \mathrm{C}$ for charging [15]. Temperature distribution across a battery pack is affected by numerous factors such as environmental variations, the physical structure of the battery pack, and charge and discharge cycles. The physical structure of the battery pack can be optimized in the design stage to guarantee proper heat dissipation. At the design stage, high fidelity three-dimensional (3D) models [16] are usually employed to develop an optimal structure. On the other hand, the environment and the battery current profile act as disturbances to the temperature distribution inside the pack. Despite these factors, the temperature inside the battery pack, as well as individual cell temperatures, should be maintained in prescribed ranges in order to ensure safe and efficient battery operation. It is graphically demonstrated in [15] that temperatures that are to low and too high can result in safety hazards and/or battery performance degradation. Therefore, a proper thermal management system is of great importance. As mentioned earlier, the BMS is responsible for thermal management in Li-ion batteries to guarantee their safety, efficiency and prolonged life.

One of the most important BMS functionalities for Li-ion batteries is protection against operating beyond safe voltage and current limits. Battery manufacturers specify low and high voltage and current limits for each battery chemistry. As described in [17], violating these limits can have a wide range of undesirable effects from minor damage to the complete destruction of a battery to fire and explosion. Therefore, in order to increase the battery lifetime and ensure a safe and reliable operation, individual voltage and current values should be monitored constantly during its operation. As soon as any battery limit is approached, the BMS should take a corrective action in order to protect the battery. The BMS reaction to any of these phenomena can be in the form of interrupting the current or limiting it to a safe value. Recently, researchers are trying to develop more advanced BMSs that are capable of determining less conservative current and voltage thresholds [11]. These works focus on electrochemical battery models in order to develop algorithms to extract maximum energy while ensuring a safe operation.

State estimation mainly involves SOC and SOH estimation. The estimation is needed because these states are not usually measurable. The definition of SOC is the ratio of available battery capacity to its fully charged capacity. State of Charge is an indication of how much longer the battery will be able to power the device. State of Health, on the other hand, does not have an agreed upon definition. It can be defined based on change of battery capacity, internal resistance, alternating current (AC) impedance, self-discharge rate, or power density [14]. However, $\mathrm{SOH}$ is mainly used to analyze battery status 
compared to a new battery. There is a vast body of literature on battery state estimation, especially SOC estimation. Lu et al. [14] provide a comprehensive overview of different SOC estimation algorithms including their advantages and disadvantages, application, and corresponding estimation error. It should, however, be noted that the majority of these methods are designed for a single battery cell rather than a pack, and issues regarding battery pack $\mathrm{SOC}$ and $\mathrm{SOH}$ estimation have not received much attention in the literature. The developed testbed will be employed to investigate different practical SOC and SOH estimation methods with a special focus on battery packs.

In this paper, the development of an experimental $\mathrm{Li}$-ion research testbed is described. This testbed is intended to facilitate in-depth research on BMS design and implementation. Important considerations that need to be taken into account while designing an advanced BMS are introduced; furthermore, various BMS subsystems are described. The experimental testbed provides three separate research platforms to test and study BMS technologies. The first platform focuses on cell level characterization, modeling, and protection system design. The second platform is specifically intended to address cell balancing by comparing currently available algorithms and developing optimal cell balancing strategies. The last research platform will address battery pack challenges and issues such as thermal management, individual and pack SOC estimation, and finally, protection system design for the entire battery pack. The test results will enable the development and improvement of novel BMS technologies with the goal of achieving safe, reliable, and efficient Li-ion battery systems. Some of the capabilities of the research testbed are illustrated through experimental results. The main contribution of this work is its focus on studying the technologies and challenges of entire Li-ion battery systems. These challenges are introduced during the description of the experimental testbed development. This paper not only addresses technical problems regarding Li-ion batteries and BMSs, it also sheds light on practical considerations in battery system development. To the authors' knowledge, this paper is the first work that addresses practical system development in parallel with theoretical and technological challenges in this field from cell to pack level.

\section{Experimental Li-Ion Battery Research Testbed}

In this section, some of the general design considerations during battery system development are discussed. These considerations include the requirements for protection circuitry, sensors, processing and data acquisition system, and BMS complexity. Furthermore, individual system components that are chosen based on these considerations are introduced and discussed.

Protection circuitry includes all the circuits and devices that are used to protect the battery from undesirable scenarios such as over/under voltage, current, and temperature. A typical response to such a scenario is current interruption. Current interruption is usually achieved by using fuses and relays or contactors. Fuses are used to autonomously interrupt the current once it maintains a certain level for a certain amount of time. The most important parameters in choosing a fuse for a specific battery application are the voltage rating, current rating and opening time. The relationship between the opening time and current is usually provided by the manufacturer in the form of a graph. Relays or contactors are other means of interrupting the current by an external command. Contact voltage and current ratings and coil voltage and current ratings are among the important parameters to consider when selecting a relay. The majority of high power relays and contactors require a drive or an amplifier in order to open/close 
using digital output signals. Another form of protection can be achieved by limiting the battery current to a set value. Current limiting is usually performed by commanding the battery load controller to facilitate drawing a lower current.

Accurate, reliable, and cost-effective sensing is undoubtedly one of the most important requirements of any battery system. In addition to being used in signal monitoring, voltage, current, and temperature measurements in batteries are used in battery protection, cell balancing, and state estimation. In addition to the sensor's sensitivity and accuracy, its robustness to changes in the ambient conditions is also very important. Considering the great importance of voltage measurement in different BMS functionalities, a voltage measurement technique with a precision of approximately a few millivolts is desirable for most applications [14]. Furthermore, in bigger battery packs, a large number of battery cells necessitate the use of numerous voltage sensors, which in turn induces noise susceptibility and common mode rejection issues. Li [18] summarized different voltage measurement technologies. Current measurement, on the other hand, is mainly performed in three ways, namely, shunts with and without galvanic isolation, open-loop Hall effect sensors, and closed-loop Hall effect sensors. In addition to the aforementioned factors, there are many application-specific factors such as linearity, hysteresis, current range, output signal range, gain stability with respect to temperature variations, etc., which affect the choice of current sensors [19]. As the number of current sensors required in a typical battery system is considerably smaller than the number of voltage sensors, there are less strict cost limitations on selecting current sensors. There are not many studies on the choice of temperature sensors for Li-ion battery systems. Temperature measurements are typically used for monitoring and protection of individual cells and/or the entire pack. Therefore, sensor sensitivity and range are among the most important factors when selecting a temperature sensor for battery systems. It is worth mentioning that there is not a best choice in selecting the sensors for Li-ion battery systems. Sensor selection should be done based on BMS requirements, system scale, and cost considerations. In summary, sensitivity, output type and level, and robustness are the most important criteria when selecting sensors for Li-ion batteries.

In large scale Li-ion battery systems, electronic control units (ECUs) or microcontrollers may be used for data acquisition, processing, storage, and communication with sensors and also outside systems. Restrictions on data acquisition and processing include sampling rate and resolution, clock frequency and processing power. The data storage capacity depends primarily on the BMS architecture and system requirements. For example, advanced BMS technologies that use electrochemical models for battery management require an extensive amount of storage memory. As mentioned earlier, the BMS needs to communicate with lower-level sensors to acquire the measurements and also coordinate with higher-level outside systems. The main communication protocol used in Li-ion BMSs is controller area network (CAN). This protocol, which was originally introduced in 1986 by Bosch for the automotive industry [20], has recently gained widespread acceptance in a large number of applications.

While the specific methods may be different for different battery chemistries [21], some of the BMS functionalities such as protection, cell balancing, and state estimation are common to different Li-ion battery systems. However, as mentioned earlier, one of the main obstacles facing Li-ion batteries is their cost. Depending on the cost limitations and system requirements, some other tasks might be required from BMSs, or some of the aforementioned functionalities might be performed using more advanced techniques. Active cell balancing and thermal management versus passive methods and advanced SOC and $\mathrm{SOH}$ estimation algorithms versus traditional algorithms are some of the BMS 
responsibilities that are usually more costly. These methods require large processing power and storage capabilities. They might also need more expensive equipment during implementation.

The battery cells chosen for the experimental testbed presented in this paper are $20 \mathrm{~A} \mathrm{~h}, \mathrm{LiMnPO}_{4}$ prismatic cells manufactured by GBS (Zhejiang, China). These prismatic cells offer high energy density, safety, and improved cycle life. They are also easier to assemble in battery packs compared to pouch cells. Some of the important specifications of the $\mathrm{LiMnPO}_{4}$ battery cells, provided by the manufacturer, are summarized in Table 1.

Table 1. $\mathrm{LiMnPO}_{4}$ battery cell specification [22].

\begin{tabular}{ccc}
\hline Specification & Value & Unit \\
\hline Nominal capacity & 20 & $\mathrm{~A} \mathrm{~h}$ \\
Single cell charging voltage limit & 3.8 & $\mathrm{~V}$ \\
Single cell discharging voltage limit & 2.5 & $\mathrm{~V}$ \\
Maximum continuous discharge current & $3 \mathrm{C}$ & $\mathrm{A}$ \\
Maximum impulse discharge current & $10 \mathrm{C}$ & $\mathrm{A}$ \\
Maximum charging current & $3 \mathrm{C}$ & $\mathrm{A}$ \\
Standard charging current & $0.3 \mathrm{C}-0.8 \mathrm{C}$ & $\mathrm{A}$ \\
Best charging current & $0.5 \mathrm{C}$ & $\mathrm{A}$ \\
Single cell cycle life at 80\% depth of discharge (DOD) & $\geq 1500$ & times \\
Charging temperature & $>0$ & ${ }^{\circ} \mathrm{C}$ \\
Discharging temperature & -20 to 65 & ${ }^{\circ} \mathrm{C}$ \\
Self-discharge rate & $\leq 3$ & $\%$ \\
Energy density & $85-100$ & $\mathrm{~W} \mathrm{~h} / \mathrm{kg}$ \\
Power density & $>800$ & $\mathrm{~W} / \mathrm{kg}$ \\
\hline
\end{tabular}

Two types of controllers (processers) are implemented in the experimental system. The first unit is a PXI chassis from National Instruments (Austin, TX, USA). An NI-PXI-6229 multifunction card with 32 analog input channels with 16 bit resolution and a $250 \mathrm{kS} / \mathrm{s}$ sampling rate, four analog output channels with 16 bit resolution and a $833 \mathrm{kS} / \mathrm{s}$ update rate, and 48 digital I/O channels is utilized inside the PXI chassis. National Instrument's LabVIEW is used as the computer interface. The reason for the inclusion of this controller is its reliability, high resolution for accurate measurements, high processing power for computationally challenging algorithms and data storage capacity for lengthy Li-ion characterization tests. In addition to the PXI chassis, an Arduino Mega microcontroller (SmartProjects, Strambiro, Italy), which is a board based on the ATmega1280, is also utilized. The Arduino has 16 analog inputs with 10 bit resolution that can be sampled at $10 \mathrm{kS} / \mathrm{s}$ and 54 digital I/O (14 of which can be used as PWM outputs). Despite the lower computational and storage capabilities of the Arduino Mega microcontroller, as compared to the NI system, it is very suitable for on-board and real-time applications due to its low cost. Considering BMS cost requirements, microcontrollers would be the ideal choice for most of the cases. Therefore, the Arduino microcontroller is included in the experimental system to facilitate research on the real world computational, storage, and communication issues facing BMS applications. It should be noted that PXI Chassis and Arduino microcontroller will be used individually, in order to handle BMS implementation from research and real-world points of view, respectively. 
The voltage sensor used for individual cell and pack voltage measurements is a Phidgets precision voltage sensor (Phidgets Inc., Calgary, AB, Canada). It provides voltage measurements in the range of $-30 \mathrm{~V}$ to $30 \mathrm{~V}$ with $\pm 0.7 \%$ typical measurement error. The senor output is a voltage between $0 \mathrm{~V}$ and $5 \mathrm{~V}$. Two types of current sensors are used in the experimental testbed. The first type, which is based on an ACS714 Hall effect-based linear current sensor from Allegro (Allegro MicroSystems, LLC, Worcester, MA, USA), is able to measure bidirectional DC currents up to $30 \mathrm{~A}$ with a sensitivity of $66 \mathrm{mV} / \mathrm{A}$. It will be used to monitor current flows in cell balancing circuitry. The other current sensor which is used for the pack current measurements is based on Allegro's ACS758 Hall effect-based current sensor IC. It is capable of measuring bidirectional currents up to $100 \mathrm{~A}$ with a sensitivity of $20 \mathrm{mV} / \mathrm{A}$. Finally, temperature measurements across the battery cells and pack are acquired using LM35 precision centigrade temperature sensors from Texas Instruments (Dallas, TX, USA). They have a linear scale factor of $10 \mathrm{mV} /{ }^{\circ} \mathrm{C}$ and are rated for $-55^{\circ} \mathrm{C}$ to $150{ }^{\circ} \mathrm{C}$.

The desired maximum current for the overall system is $100 \mathrm{~A}$. Therefore, the protection circuitry which comprises of a fuse and a contactor is chosen accordingly. The selected fuse is a 40 A bolt-down fuse from Littlefuse (Chicago, IL, USA) which is rated for $32 \mathrm{VDC}$ and interrupting current of $2000 \mathrm{~A}$ at 32 VDC. Figure 2 shows the opening time versus current value for a family of this fuse. As can be seen from this figure, it takes about $5 \mathrm{~s}$ at a current value of $100 \mathrm{~A}$ for the fuse to open.

Figure 2. Characteristic curve for a $32 \mathrm{~V}$ rated Mega fuses from Littlefuse.

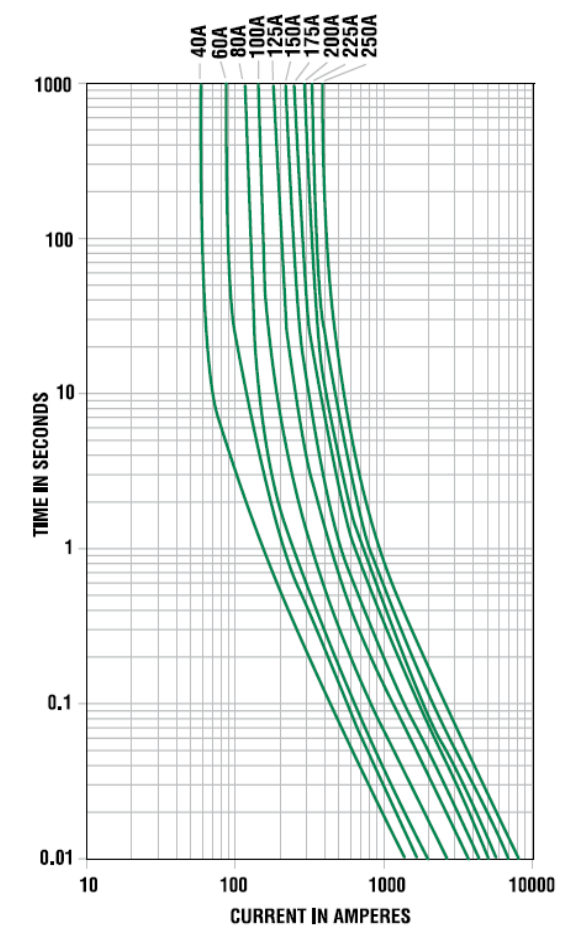

The protection unit has a $600 \mathrm{VDC}, 100 \mathrm{~A}$ hermetically sealed DC contactor. Its coil is rated for 9-32 VDC and a maximum pickup current of $1-5 \mathrm{~A}$ at $20^{\circ} \mathrm{C}$. A MOSFET amplifier is designed in order to drive the contactor with the digital output from the controller.

Finally, a programmable power supply and electronic DC load pair from BK Precision (Yorba Linda, CA, USA) is used in order to charge and discharge the battery. The programmable power supply (model number XLN6024) is capable of delivering $1.44 \mathrm{~kW}$ power in constant current and voltage modes. 
The model 8514 programmable DC load can absorb a maximum power of $1.2 \mathrm{~kW}$ in constant current, voltage, resistor, and power modes. Communication with the DC load and power supply is established through serial ports using NI LabVIEW.

The experimental $\mathrm{Li}$-ion research testbed is designed to operate in three configurations in order to cover a wide variety of research areas in Li-ion battery systems. The first configuration is a single cell research platform. The focus of this platform, which is shown in Figure 3, is to perform different tests on individual battery cells. These tests target electrical and thermal characterization and modeling of the individual cells and the analysis of discrepancies between seemingly identical cells. Efficient thermal and electrical protection unit architectures can also be studied. Finally, high power performance and modeling analysis for battery cells can be addressed using this platform.

Figure 3. Single cell research platform with its schematic diagram.
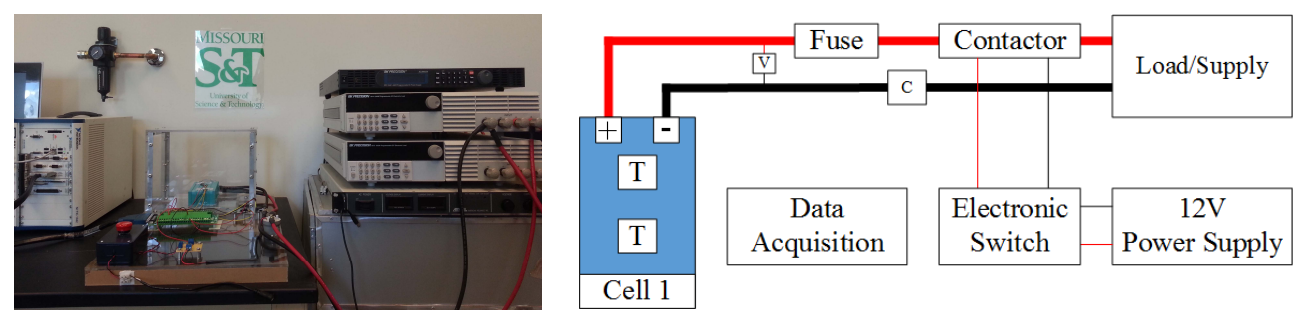

The second platform addresses cell balancing during battery operation. Cell balancing is undoubtedly the most significant during charging as any imbalance among cells can result in overvoltage and, therefore, safety hazards. In order to study this important functionality, the second platform consists of three battery cells in series with each other. In addition to individual voltage sensors for cells, they are also equipped with individual current sensors to facilitate examining their current and, therefore, capacity evolution during different cell balancing strategies. This configuration is depicted in Figure 4.

Figure 4. Cell balancing research platform with its schematic diagram.
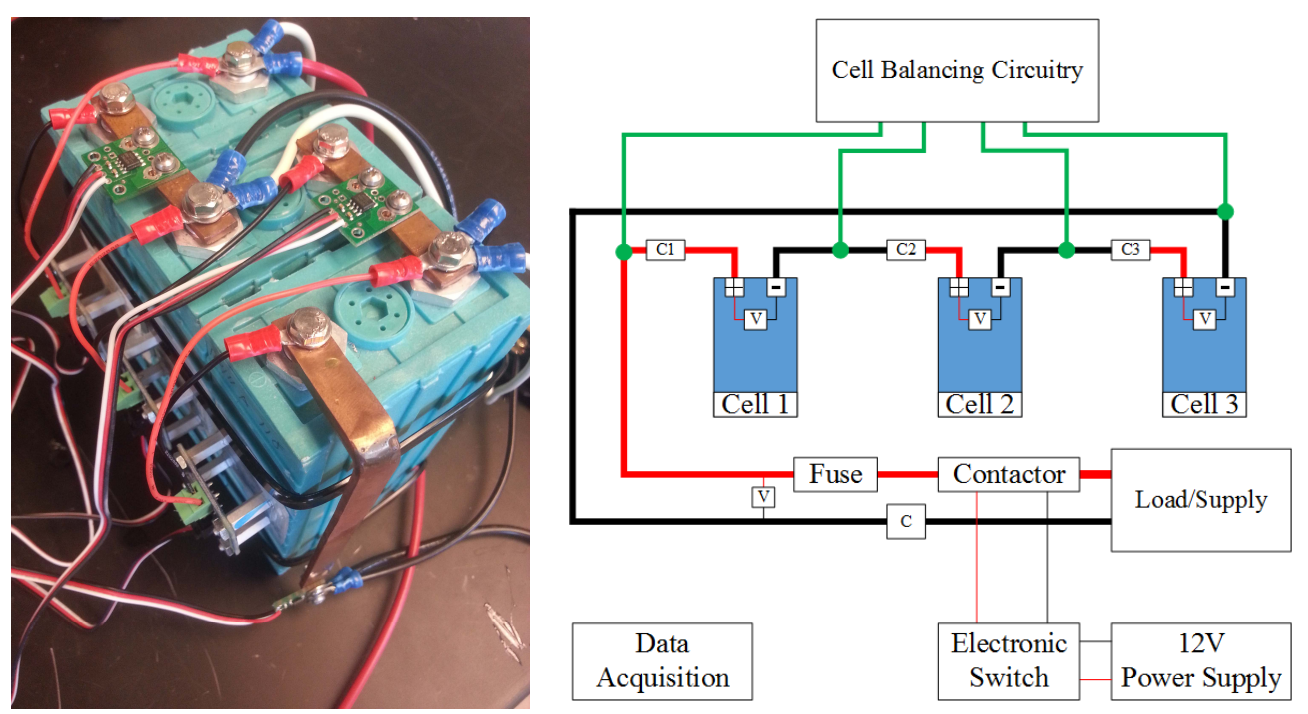

The last platform is a complete eight cell battery pack with voltage and temperature sensors for each cell and a pack current and voltage sensor. This platform is devised to address issues encountered in battery packs such as battery pack modeling and state estimation, temperature distribution and 
thermal management, a cell balancing strategy addressing both charging and discharging, and efficient electrical protection of the battery packs. Figure 5 shows the battery pack setup with its corresponding schematic diagram.

Figure 5. Battery pack research platform with its schematic diagram.
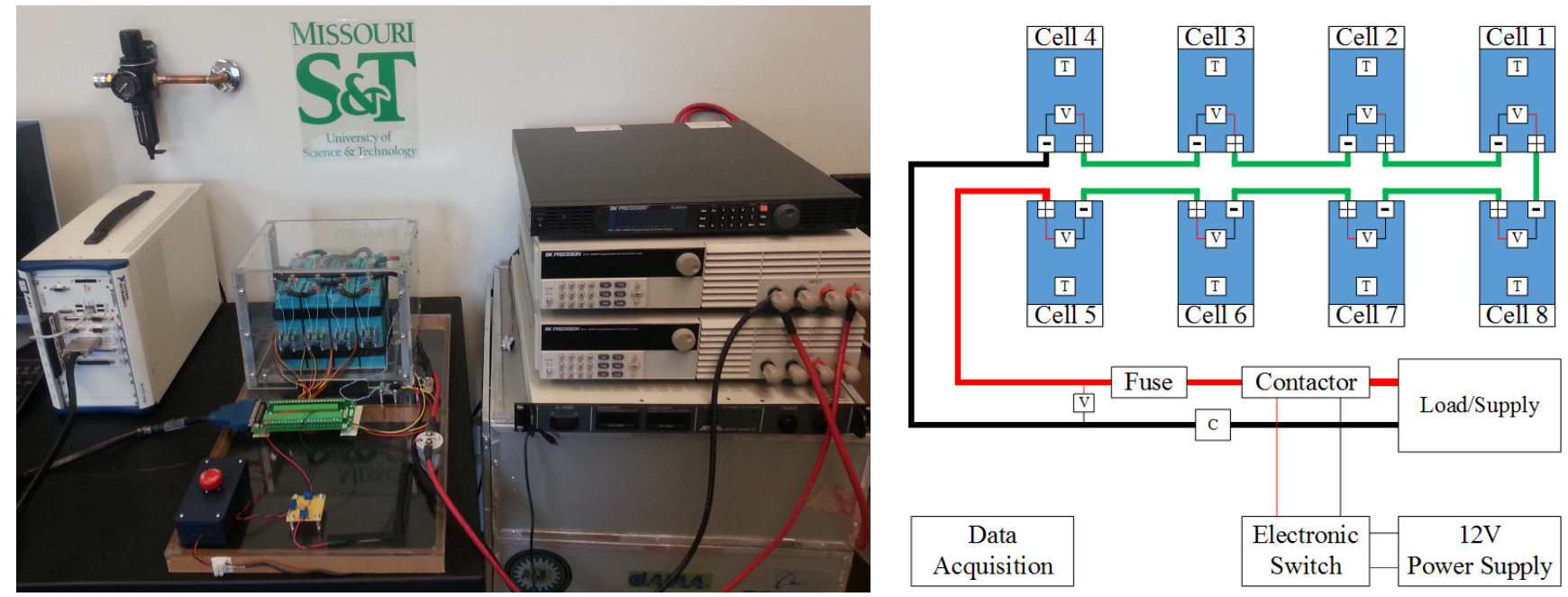

In the following sections, different BMS functionalities are discussed in more detail. Considerations that should be taken into account in designing each subsystem and future improvements that can be integrated in BMS technologies are introduced. Some initial characterization test results are also reported.

\section{Experimental Battery Characterization and Modeling}

Battery characterization, for both cells and packs, is the initial stage in any battery system development. It aims to validate the battery parameters given in the manufacturer datasheet and identify those not provided by the manufacturer. Furthermore, it provides additional information that might be required by the BMS. This additional information includes electrochemical battery parameters, charge and discharge capabilities, temperature distribution, etc. Some of the battery characterization procedures such as GITT, PITT, impedance spectroscopy, and CV provide internal information about battery performance and structure. These tests require advanced testing equipment and are usually conducted by electrochemists. On the other hand, characterization tests such as the ones proposed by the Partnership for a New Generation of Vehicles or FreedomCAR [8] mainly deal with external battery performance. These tests typically make use of voltage, current, and temperature sensor measurements. Both types of characterization tests can provide the means of identifying different battery model parameters. An overview of different battery models and their applications will follow the characterization subsection. Temperature distribution along the cells and the pack and also the temperature effect on battery performance is not included in this paper and will be studied in the future work.

\subsection{Characterization}

The characterization tests that will be run on individual battery cells are chosen among the enhanced tests proposed in [4]. It should, however, be noted that charge and discharge current magnitudes for these 
tests are modified due to limitations on the power supply and electronic load ratings. These tests cover the majority of general characterization experiments required for battery system development. The characterization tests are initialized with a charge/discharge cycle of $0.5 \mathrm{C}$, which corresponds to $10 \mathrm{~A}$. Figures 6 and 7 show the evolution of battery signals during this charge/discharge, respectively.

Battery charging is performed in constant current constant voltage (CCCV) regime. This is a common battery charging scenario in which a constant current is applied to the battery until its voltage reaches a specified upper limit (in this case $3.8 \mathrm{~V}$ ). At this voltage limit, the battery will be kept at a constant voltage until its current decays to zero. Charge and discharge profiles are terminated according to upper/lower voltage limits prescribed by the manufacturer. As can be seen in Figures 6 and 7, despite the fact that the cells have a $20 \mathrm{~A} \mathrm{~h}$ capacity, this nominal capacity cannot be achieved during charge/discharge. The reason for this can be attributed to either inaccurate upper/lower voltage limits in the protection subsystem or incorrect battery nominal capacity. These results magnify the need for characterization tests before any battery system development. Determination of exact battery capacity will be studied in the next subsection. On the other hand, choosing appropriate protection limits for the battery is discussed in the protection system subsection. The rest of the characterization tests are described below.

Figure 6. Battery charge profile.
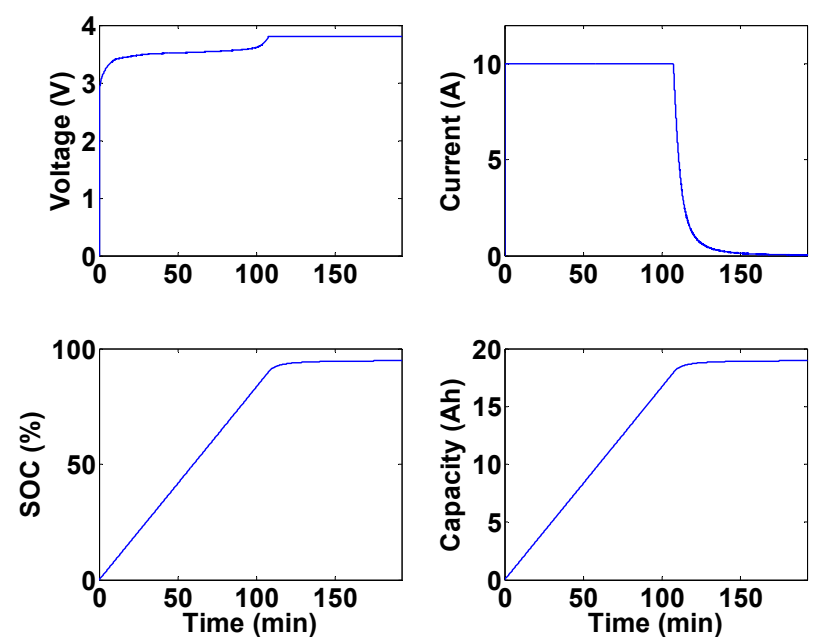

Figure 7. Battery discharge profile.
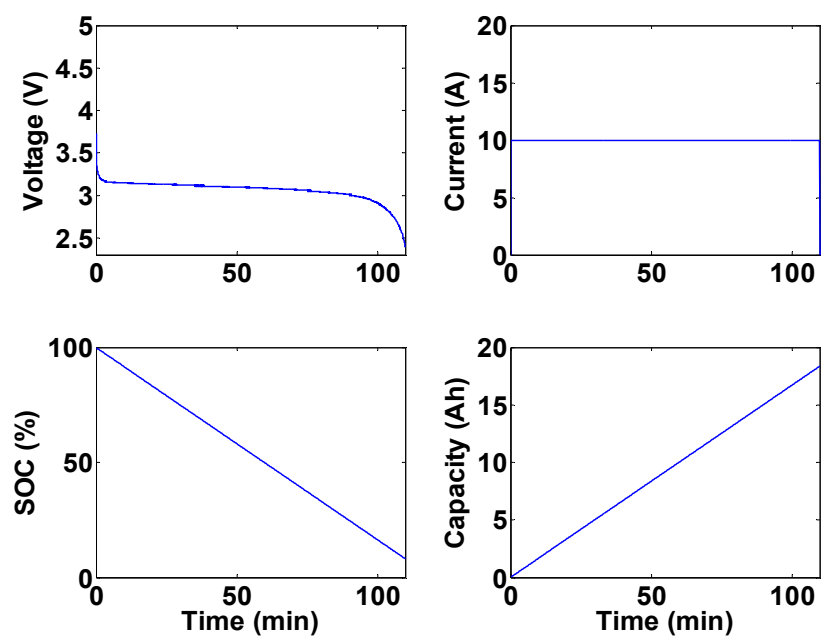


\subsubsection{Static Capacity Test}

The static capacity test is performed at three discharge rates of $0.5 \mathrm{C}, 1 \mathrm{C}$, and $2 \mathrm{C}$. Charging, on the other hand, is performed at rates of $0.5 \mathrm{C}, 1 \mathrm{C}$, and $1 \mathrm{C}$. Charging rate is always kept below or equal to $1 \mathrm{C}$ in order to ensure safe charging. After each (dis)charge, the cell is allowed to rest for approximately half an hour. Figures 8 and 9 illustrate battery voltage, current, SOC, and capacity evolution during these three discharge tests.

Figure 8. Voltage and current evolution during discharge tests for static capacity determination.
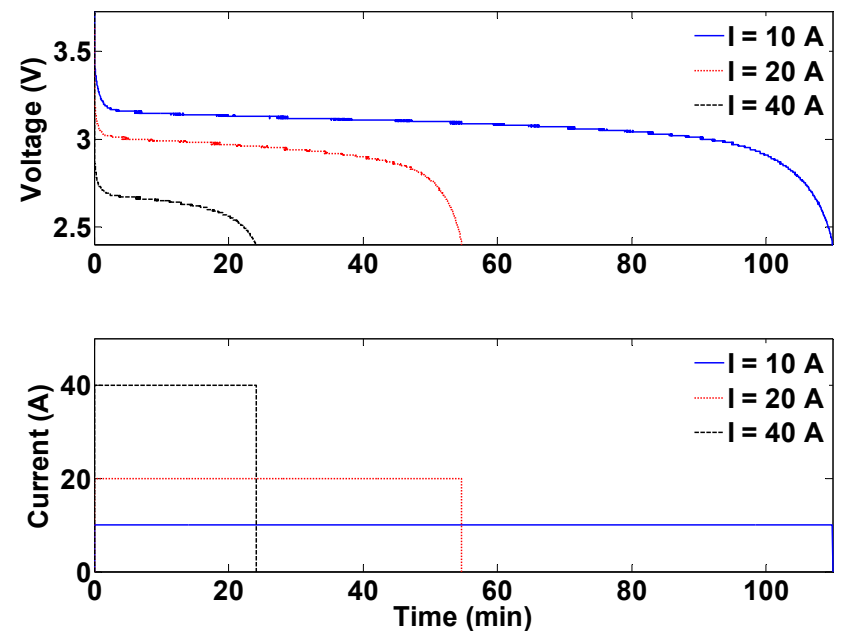

Figure 9. State of charge (SOC) and capacity evolution during discharge tests for static capacity determination.
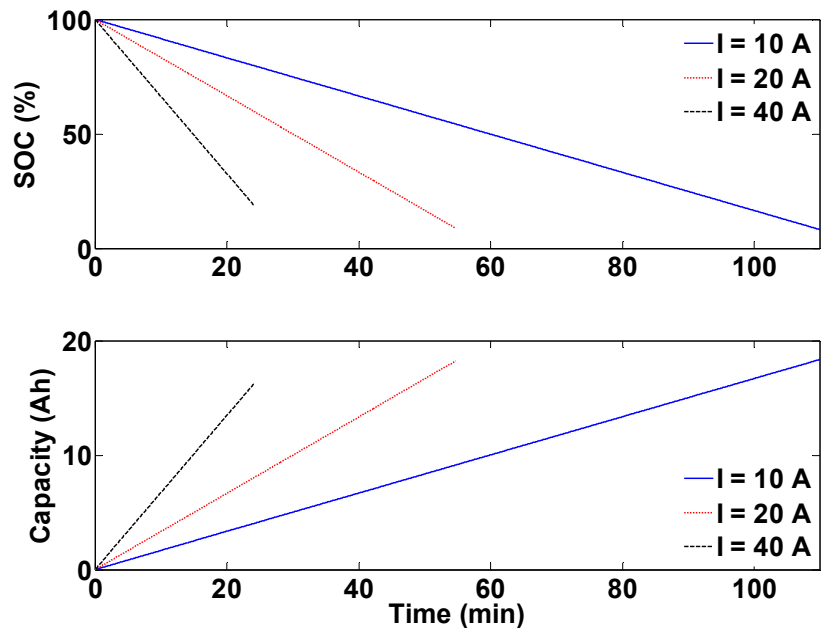

It can be seen from Figures 8 and 9 that battery capacity is dependent on discharge current rate. The same holds true for charging current. Table 2 includes battery capacity values for different charge and discharge current rates. 
Table 2. Battery capacity values.

\begin{tabular}{ccc}
\hline \multirow{2}{*}{ Current (A) } & \multicolumn{2}{c}{ Battery capacity (A·h) } \\
\cline { 2 - 3 } & Discharge & Charge \\
\hline 10 & 18.35 & 18.67 \\
20 & 18.23 & 18.95 \\
40 & 16.21 & - \\
\hline
\end{tabular}

Battery capacity tests are not performed with 40 A charging current and that is the reason, the corresponding capacity is not reported in Table 2. Battery capacity change due to its current rate is usually characterized by Peukert's Law, which is an empirical relationship [23]:

$$
\Delta C=\left(I_{t}\right)^{\gamma} t
$$

where $\Delta C$ is the battery capacity change (A.h); $I_{t}$ is battery terminal current (A); $\gamma$ is the Peukert constant, which is usually between 1.05 and 1.3; and $t$ is the corresponding charge/discharge time (h). Battery capacity change due to its current rate is usually ignored in BMS design which might introduce errors. This effect will be considered in the BMS design for the experimental testbed.

\subsubsection{HPPC Test}

The HPPC test is a commonly used test profile, comprising charge and discharge pulses, that is used to determine the battery's dynamic power capabilities during its operation. Its main objective is to determine, according to some pre-defined requirements, the maximum and minimum battery voltage levels, as a function of depth of discharge (DOD), after charge and discharge pulses, respectively. These requirements are usually based on goals established for the FreedomCAR energy storage development program by the Idaho National Engineering and Environmental Laboratory (INEEL, Idaho Falls, ID, USA) [8]. The HPPC test can also be used to derive battery equivalent-circuit model parameters. These parameters are used in simulating battery behavior as well as determining battery status in its life cycle tests. The HPPC test profile is shown in Figure 10.

Figure 10. Hybrid pulse power characterization (HPPC) test profile [8].

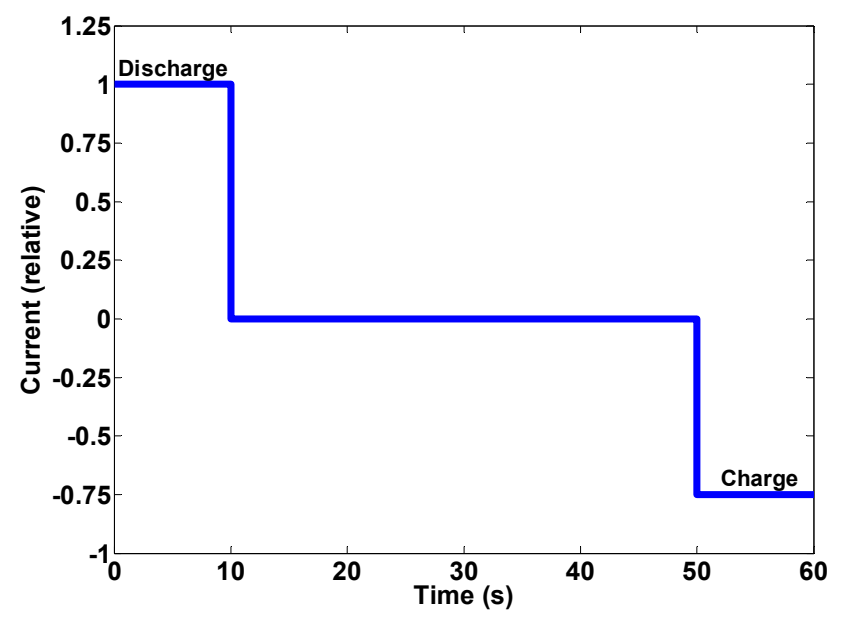

The current values shown in Figure 10 are relative and their actual values are determined based on the rated maximum current scaled to two different values: in the low current HPPC test, the pulse discharge 
current is $25 \%$ of the absolute maximum pulse discharge current specified by the manufacturer for $10 \mathrm{~s}$. However, if the manufacturer does not specify the maximum pulse current, the maximum pulse current will be taken as the $5 \mathrm{C}$ rate. In the high current HPPC test, the pulse discharge current is taken as $75 \%$ of the maximum pulse current. As mentioned earlier, due to power supply and electronic load constraints in the experimental system, the current values for the HPPC experiments are taken as: $20 \mathrm{~A}$ continuous discharge current, 40 A pulse discharge current, 16 A continuous charge current, and $20 \mathrm{~A}$ pulse charge current.

Overall, the HPPC procedure is comprised of nine repetitions of the profile shown in Figure 10, separated by a $10 \%$ DOD constant current discharges at a $1 \mathrm{C}$ rate. The constant current discharge is followed by an hour rest period. The rest period is intended to let the battery reach thermal and electrochemical equilibrium. This procedure is continued until 90\% DOD is achieved, after which another $1 \mathrm{C}$ rate discharge is performed until the battery reaches $100 \%$ DOD. Figure 11 shows a complete HPPC test sequence.

Figure 11. Complete HPPC test sequence.

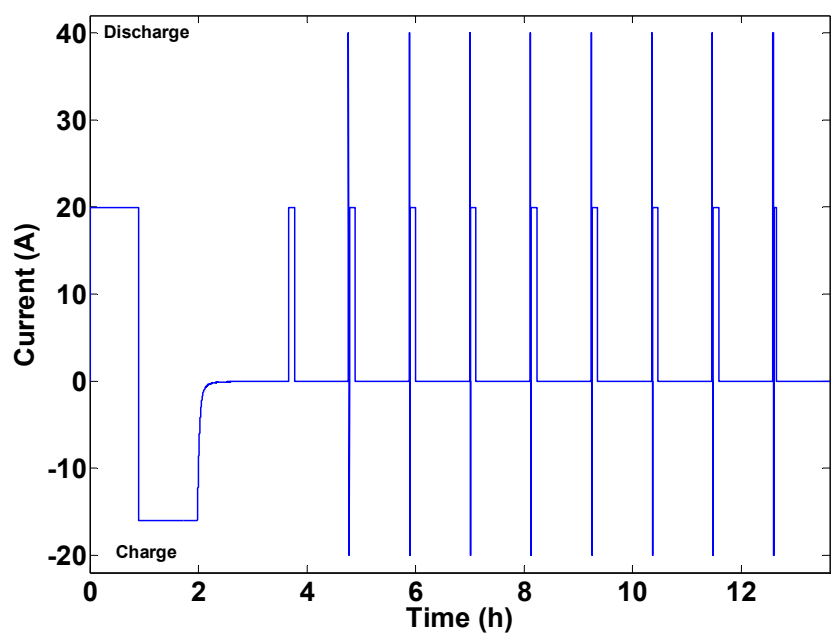

The time evolution of battery voltage and SOC during the HPPC profile is shown in Figure 12.

Figure 12. Battery voltage and SOC evolution during HPPC profile.
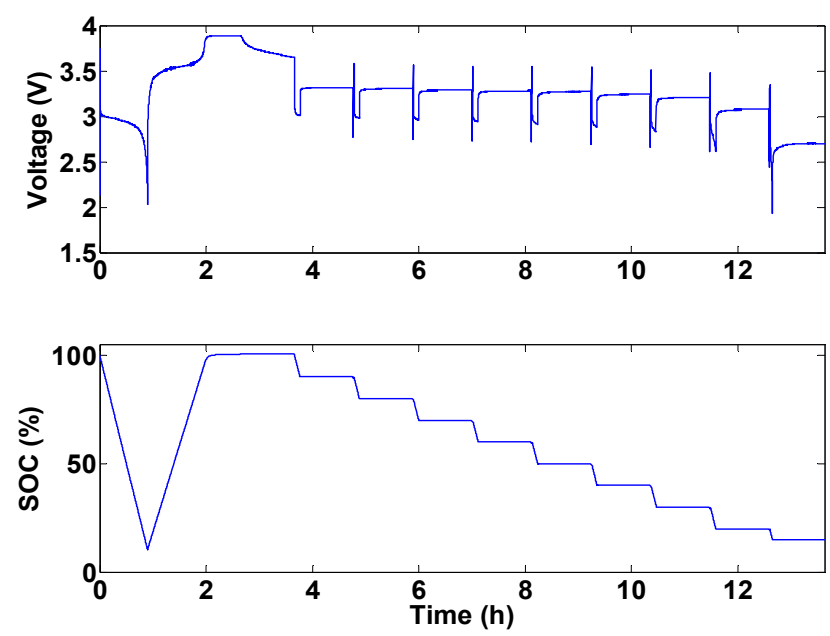
The HPPC test on the experimental testbed is interrupted at 90\% DOD in order to ensure battery safety. Analysis details of HPPC test results can be found in Section 4 of FreedomCAR Battery Test Manual for Power-Assist Hybrid Electric Vehicles [8].

\subsubsection{Open-Circuit Voltage Test}

Open-circuit voltage tests are comprised of nine repetitions of constant current, fixed discharge intervals. As an example, starting with a fully charged battery, it is discharged with a current of $0.5 \mathrm{C}$ until it reaches $90 \%$ SOC. After a rest period of about half an hour, the battery is discharged again with the same current until it reaches $80 \%$ SOC. A similar rest period is then included. These discharge-rest sequences are repeated until the battery SOC reaches 10\%. Figure 13 shows the first open-circuit voltage test that starts from $\mathrm{SOC}=100 \%$.

Figure 13. First step in open-circuit voltage tests.
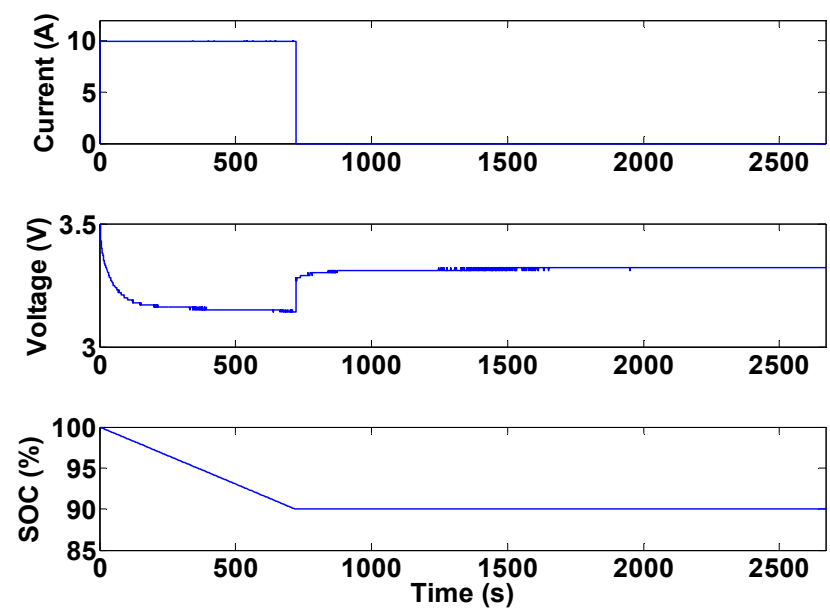

Figure 14. Battery open-circuit voltage and internal resistance versus SOC.
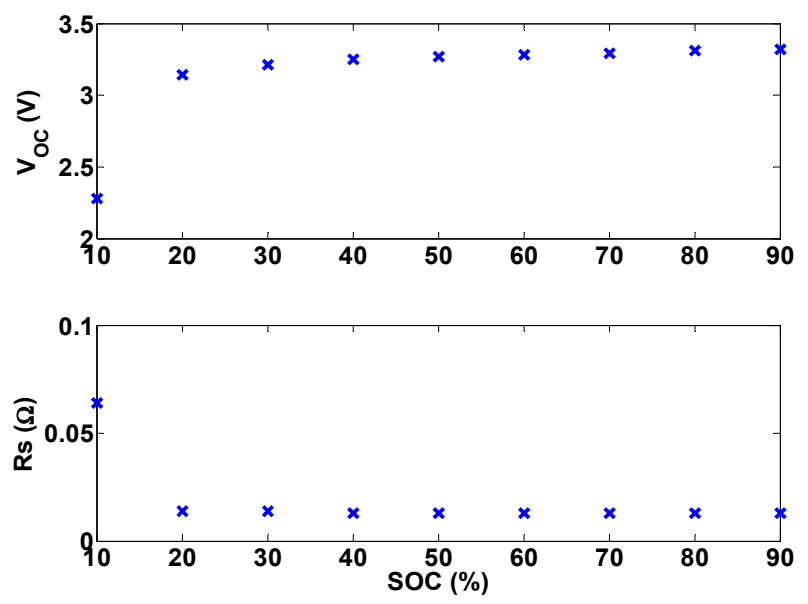

Open-circuit voltage tests are mainly used to determine the exact relationship between battery SOC and open-circuit voltage. The rest periods in these tests are included in order to allow the battery terminal voltage to reach its equilibrium point so that it can be considered as the battery open-circuit voltage. The test results can also be used to identify model parameters such as internal resistance and resistor-capacitor (RC) networks values [24]. Figure 14 demonstrates battery open-circuit voltage and 
internal resistance as a function SOC based on the results of open-circuit tests. The open-circuit voltage values are obtained from the steady-state battery voltage measurements. Battery internal resistance, on the other hand, can be calculated by dividing the voltage difference right before and after current interruption by the current. In other words, if the voltage increase in Figure 13 at the instance of current interruption is $\Delta V$, the internal resistance at $\mathrm{SOC}=90 \%$ would be $\Delta V / 10$.

\subsection{Modeling}

There are numerous works in the literature on Li-ion battery modeling. The complexity and structure of the battery model greatly depends on the application requirements. High fidelity electrochemical models describing the performance of Li-ion batteries were first introduced by Doyle et al. [9]. These models have been used extensively for battery design and performance analysis. On the other hand, for real-time applications such as BMSs in which there are strict limitations on cost and processing power, equivalent-circuit models have been proposed. In these types of models, electrical circuit elements are used to describe the behavior of the Li-ion battery. Although these models do not have a high prediction capability, they require very low computational power. Hence, they are widely used in model-based BMS applications. Hu et al. [13] presented an overview of twelve commonly used equivalent-circuit battery models. According to model complexity, accuracy and robustness, these twelve models have been evaluated. The authors concluded that first-order RC model with one-state hysteresis, proposed by [25], provides the best voltage prediction. The schematic of this model is shown in Figure 15.

Figure 15. First-order resistor-capacitor (RC) model with one-state hysteresis [25].

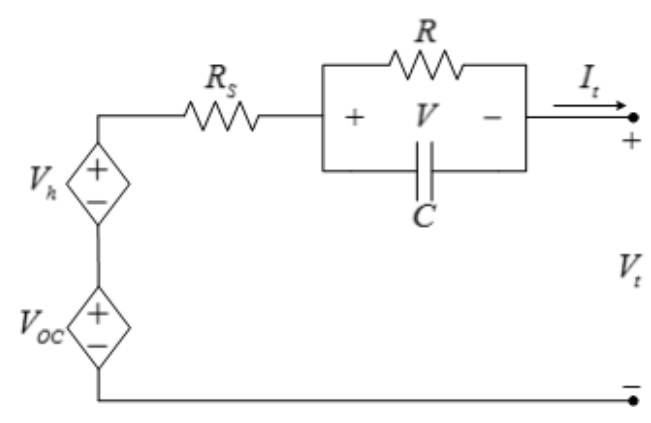

Differential equations describing the dynamics of the model illustrated in Figure 15 are:

$$
\left\{\begin{array}{l}
\frac{d z(t)}{d t}=-\frac{1}{3600 C_{n o m}} I_{t}(t) \\
\frac{d V(t)}{d t}=-\frac{1}{R C} V(t)+\frac{1}{C} I_{t}(t) \\
\frac{d V_{h}(t)}{d t}=-\beta\left(\eta_{I_{t}}-\varepsilon S_{D}\right)\left[V_{h, \text { max }}+\operatorname{sign}\left(I_{t}\right) V_{h}\right]
\end{array}\right.
$$

where $C_{n o m}$ is the nominal battery capacity $(\mathrm{F})$; and $z(t)$ is the SOC (\%). The first Equation (3) is obtained from the definition of SOC, the second equation is from Kirchhoff's current law, and the last equation is proposed in [25] to take battery's hysteresis effects into consideration. In the last equation, the term $S_{D}$ 
denotes the battery self-discharge rate which is considered to be a function of temperature and battery SOC:

$$
S_{D}(t)=k_{0} \exp \left(-\frac{E_{A, S}}{R_{g} T}\right) z(t)
$$

where $T$ is battery temperature $(\mathrm{K})$; and the parameters $\beta, \eta_{I t}, \varepsilon, V_{h, \max }, k_{0}, E_{A, S}$, and $R_{g}$ are constants to be identified. The battery output voltage can also be written as:

$$
V_{t}=V_{O C}(t)-V_{h}(t)-R_{s} I_{t}(t)
$$

One other commonly-used battery model is the equivalent-circuit model introduced in [12]. Figure 16 shows a schematic of this model. This model has been extensively used in various BMS subsystem designs including the SOC estimation subsystem [24,26].

Figure 16. Equivalent circuit battery model [12].

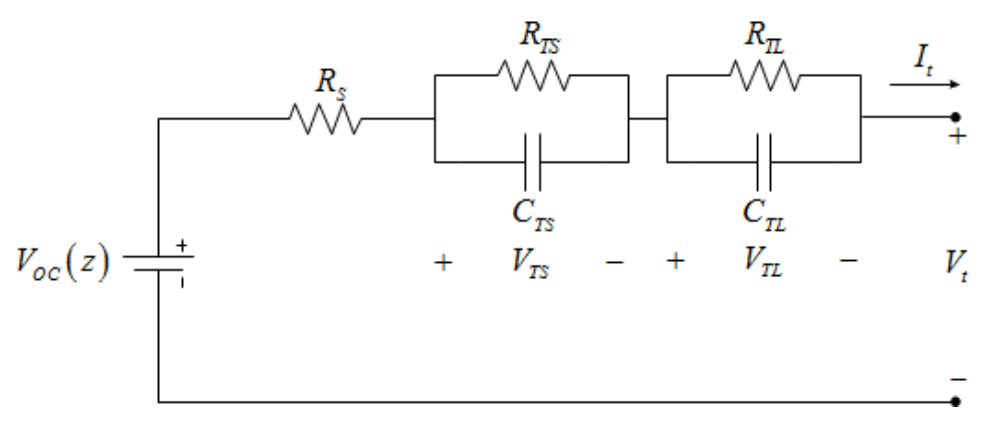

Using the SOC definition and Kirchhoff's current law for the model in Figure 16, the set of first-order differential equations describing the battery dynamics is:

$$
\left\{\begin{array}{l}
\frac{d z(t)}{d t}=-\frac{1}{3600 C_{\text {nom }}} I_{t}(t) \\
\frac{d V_{T S}(t)}{d t}=-\frac{1}{R_{T S} C_{T S}} V_{T S}(t)+\frac{1}{C_{T S}} I_{t}(t) \\
\frac{d V_{T L}(t)}{d t}=-\frac{1}{R_{T L} C_{T L}} V_{T L}(t)+\frac{1}{C_{T L}} I_{t}(t)
\end{array}\right.
$$

Furthermore, using Kirchhoff's voltage law, the output battery voltage is:

$$
V_{t}=V_{O C}(z(t))-V_{T S}(t)-V_{T L}(t)-R_{s} I_{t}(t)
$$

These two models will be used in the BMS design for the experimental research testbed. Different algorithms have been proposed to identify the model parameters of the above models. A majority of the identification procedures employ HPPC data in order to identify the model parameters. Details of model identification process can be found in [13,24,27].

It is also worth mentioning that despite the high computational cost of electrochemical models, a number of research groups have focused their attention on employing these models in BMS design, due to the models' high accuracy and prediction capability. One of the first efforts in this area was described in Santhanagopalan et al. [28]. They introduced the single particle approximation of the full 
order electrochemical models and used it for SOC estimation. Domenico et al. [29] and Moura et al. [30] used this single particle model for SOC estimation. Smith et al. [10] and Chaturvedi et al. [11] employed model order reduction techniques to facilitate on-line implementation of electrochemical models in BMSs.

\section{Cell Balancing}

Cell balancing is a technique used to establish uniformity among cells in a battery pack. Internal differences among battery cells, despite similar specifications and type, are inevitable. The imbalance among battery cells can arise from differences in voltage, SOC, capacity, internal resistance, self-discharge and their change rate [14]. An efficient balancing algorithm can be employed by the BMS to make use of the available battery pack capacity. Lack of proper cell balancing might results in under/over voltage of some battery cells in the pack which, in turn, can have undesirable effects ranging from battery life degradation to safety hazards. Cell balancing can be performed based on the voltage and remaining capacity (SOC). Due to the immaturity of SOC estimation techniques for individual battery cells and battery packs, cell balancing based on voltage uniformity is more feasible and common.

Cell balancing techniques can be divided into passive and active. In passive cell balancing, the existing excess energy or capacity among cells is wasted in a passive circuit element such as a resistor. Passive cell balancing is easy to implement and does not introduce large costs. Active cell balancing, on the other hand, employs active circuit elements such as capacitors and switches to shuttle charge between the unbalanced cells. Although active cell balancing is more efficient, it introduces complexity, unreliability, and difficulty in implementation. Current active cell balancing techniques include switched capacitor, double-tiered switched capacitor, single-switched capacitor, step up/boost converter module, and multi-winding transformers [31-34]. Some of the most common cell balancing techniques with their corresponding advantages and drawbacks are summarized below.

\subsection{Resistive Shunting}

This method of cell balancing, shown in Figure 17, is simple and effective. It is a passive method because it dissipates excess energy into heat. The system works by monitoring each cell's voltage and comparing them to one another. If a cell's voltage becomes higher than the voltages of other cells, a shunt resistor is connected across that cell using a transistor or a relay. The resistor turns the excess energy from that cell into heat until a balanced voltage is achieved among different cells.

Figure 17. Resistive shunting configuration.

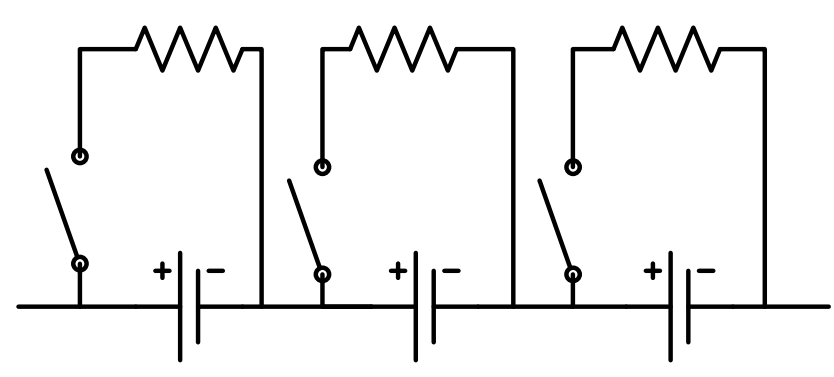

Resistive shunting is usually performed in two methods. In the first method, cell balancing is performed during the whole battery operation. As soon as a cell voltage deviates from other cells' voltage, 
the corresponding switch closes and transfers the excess charge to the resistors. The amount of energy wasted in resistors is very low due to small variances in cell voltages. However, this scenario introduces larger switching losses due to frequent switching. The second method initiates cell balancing at the end of charge cycle. In this case, once a cell reaches its maximum voltage, its corresponding switch closes and transfers the battery current to the resistor. High power resistors are usually required for this method, as large current values can pass through the resistors. The second method is not applicable for cell balancing during discharge cycles.

\subsection{Switched Capacitor}

Switched capacitor cell balancing works by shuttling charge from higher voltage cells to lower voltage cells. The circuit for a switched capacitor configuration is shown in Figure 18. The capacitors each switch between two cells. When connected to the higher voltage cell in the pair, the capacitor will be charged. On the other hand, when the capacitor switches to the lower voltage cell, it will discharge. This approach requires no intelligent control, only a clock cycle is needed to trigger the switching between cells.

Figure 18. Switched capacitor configuration.

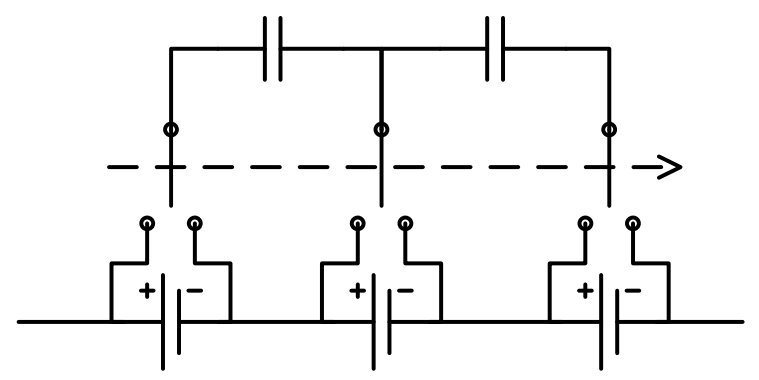

\subsection{Double-Tiered Switched Capacitor}

This method is implemented in the same way as the switched capacitor method, but with an additional tier of capacitors as shown in Figure 19. The second tier of capacitors switches between two series pairs of cells. This greatly reduces the balancing time for the pack, especially if cells with different charge levels are located far apart from one another in the pack.

Figure 19. Double-tiered switched capacitor configuration.

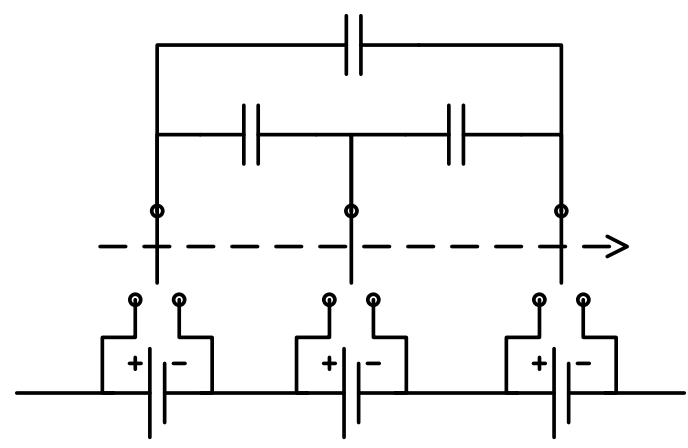




\subsection{Single-Switched Capacitor}

The single switched capacitor configuration uses one capacitor and an array of switches, as illustrated in Figure 20. The cell voltages are monitored and used to intelligently control the connections to the capacitor. Rather than cycling through individual cells, the system chooses to cycle between two cells in the pack with the greatest voltage difference.

Figure 20. Single-switched capacitor configuration.

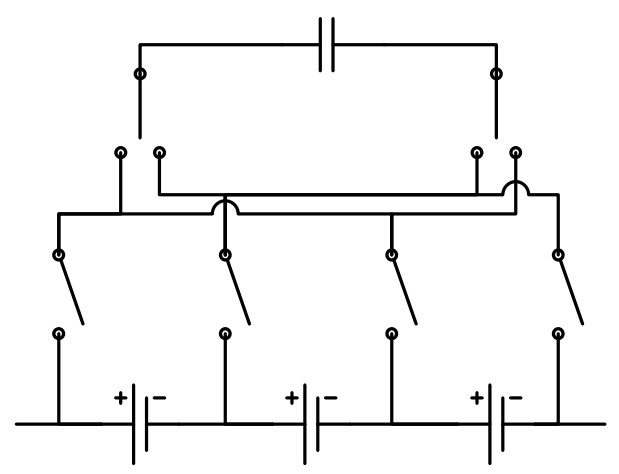

\subsection{Step-up/Boost Converter}

The step-up/boost converter balancing circuit is shown in Figure 21. The circuit is comprised of isolated converters for each cell in the series string. The inputs of the converters are connected across each cell and the outputs from the converters are paralleled across the pack. The system monitors each cell's voltage and intelligently controls the converters to remove energy from higher voltage cells and redistribute it to the rest of the cells in the pack.

Figure 21. Boost converter configuration.

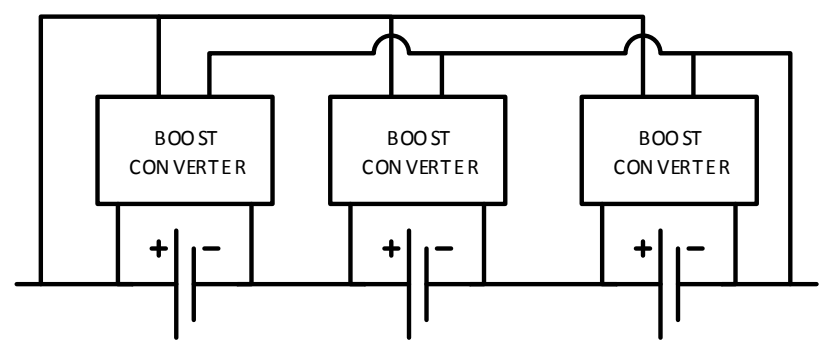

Comprehensive and in-depth comparisons between different balancing methods, discussed in this paper, are conducted in [35-37]. These studies consider cost and number of circuit components in their comparisons. There is not a single cell balancing method that is the best across all categories. Depending on the application requirements, any of these methods may be the appropriate choice. A tradeoff should be made between system cost and efficiency while designing cell balancing circuitry. An optimal switching schedule, considering system losses in order to increase the overall system efficiency, is one of the future studies to be conducted on this experimental Li-ion research testbed. 


\section{Protection}

The protection subsystem in the BMS is intended to guarantee the battery operates in its safe region. Battery voltage, current, and temperature are factors determining the safe operating region. Some of the harmful effects of running the battery outside of this region were briefly reviewed in the Introduction based on information from [15]. Two important aspects should be taken into account when designing a battery protection subsystem: when to react to a detected range violation and how to handle such a condition. In this section, these aspects will be studied for voltage, current, and temperature protection. Furthermore, the protection subsystem architecture devised for the experimental battery testbed is discussed.

The operating voltage of Li-ion batteries is dictated by their chemistry. More specifically, the material used in the cathode structure determines the battery voltage limits. For the battery chemistry used in the experimental testbed, which is described in Table 1, the operating voltage should be between $2.5 \mathrm{~V}$ and $3.8 \mathrm{~V}$. Therefore, the BMS should ensure the individual cell voltages remain in this range at all times. It should be noted that it is more efficient to impose voltage limits on the battery open-circuit voltage rather than the battery terminal voltage. However, battery open-circuit voltage is not measurable during battery operation and an estimation algorithm should be implemented to obtain battery open-circuit voltage from its measurable signals, i.e., voltage, current, and temperature. The easiest method to estimate battery open-circuit voltage is to use the equivalent-circuit model shown in Figure 22.

Figure 22. Equivalent-circuit battery model.

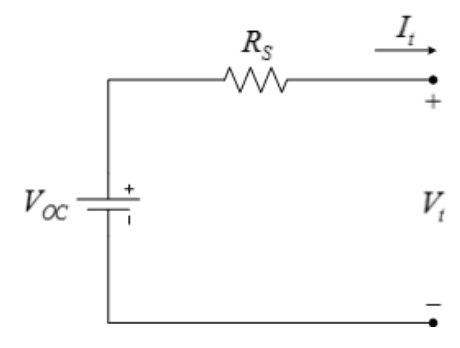

Applying Kirchhoff's voltage law to the circuit in Figure 22, the battery open-circuit voltage is:

$$
V_{O C}=V_{t}+R_{s} I_{t}
$$

where $R_{S}$ is calculated from open-circuit voltage tests, as described in Section 3.1.3. In order to estimate battery open-circuit voltage using Equation (8), the average value of $R_{S}$, which is $0.0189 \Omega$, is used.

Another method to obtain battery open-circuit voltage, assuming an accurate SOC estimate is available, is to use the open-circuit voltage-SOC relationship. This relationship can be obtained from fitting the following model to the experimental data in Section 3.1.3:

$$
V_{O C}(S O C)=3.186 \cdot \exp (0.00047114 \cdot S O C)-10.88 \cdot \exp (-0.2469 \cdot S O C)
$$

Figure 23 shows the fitted model Equation (9) and the experimental results. It is proposed in [17] that the time average of the battery terminal voltage should be used as the protection criteria instead of the terminal voltage. 
Figure 23. Experimental and modeled battery open-circuit voltage.

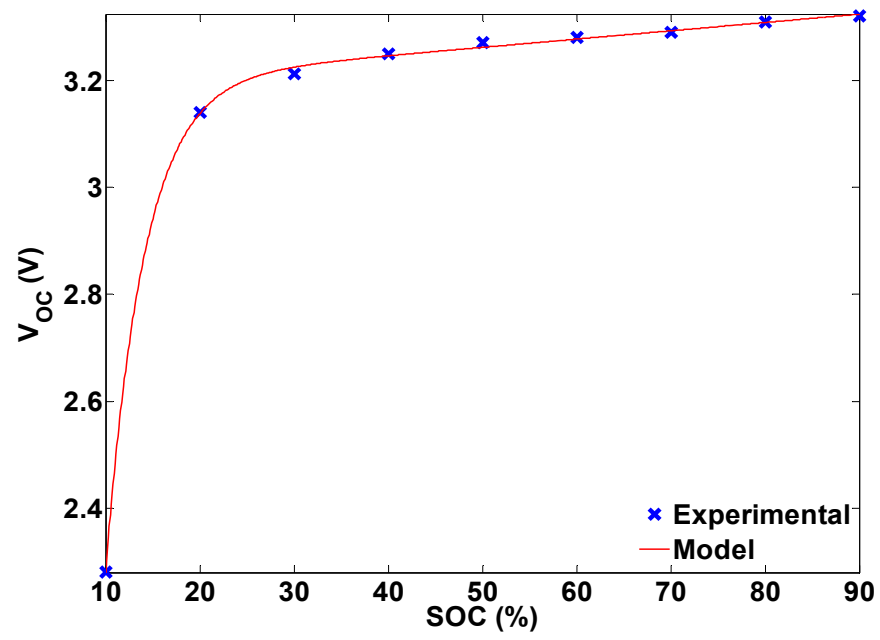

Figure 24 shows the evolution of terminal voltage, open-circuit voltage obtained using the above two methods, and the time average of terminal voltage during a complete battery discharge.

Figure 24. Comparison of different voltage levels during a discharge profile: (a) the whole profile; and (b) end of discharge.

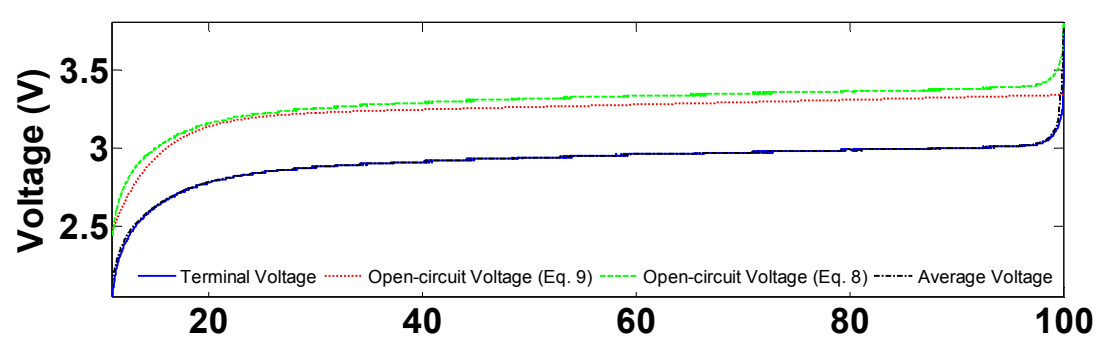

(a)

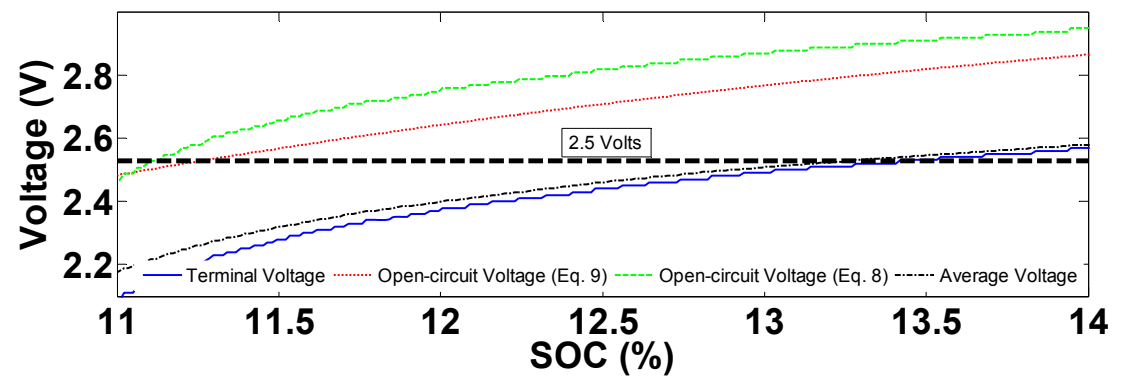

(b)

As can be seen from Figure 24, more energy can be extracted from the battery, before the manufacturer's low cut-off voltage is approached, if the open-circuit voltage obtained from Equation (8) is used in the protection system. It should however, be noted that Equation (8) is just an approximation of the open-circuit battery voltage. Substantial research is still needed in designing less conservative and more efficient Li-ion battery protection systems. The results presented in Figure 24 are obtained from a constant-current discharge profile. Investigating the performance of protection system during dynamic current profiles is also an important research topic in BMS development.

Finally, there are some recent studies which focus on observing internal battery parameters such as lithium concentration in the negative electrode instead of battery voltage as the protection criteria $[11,38]$. 
The authors claim that by considering such protection criteria for batteries more energy can be extracted while maintaining safe battery operation. More research still needs to be conducted to facilitate on-line implementation of such algorithms.

Once a voltage limit is being approached, the battery's protection system will react to it in one of the following three ways: interrupt the current, ask an external system component to interrupt the current, or communicate with the load and command it to limit the current it is drawing from the battery. The protection units, which will interrupt the current autonomously, are called protectors [17] but are not studied here. The other two reactions of the protection unit, however, are implemented in the experimental testbed. The choice of which reaction to choose depends on the application. Specifically, current limiting is usually preferred in applications where continuous current supply is vital.

The safe operating range for the battery current is usually determined by its physical structure and manufacturing specifications. As can be seen in Table 1, four current limits are specified for batteries in the datasheet: continuous charging, peak charging, continuous discharge, and peak discharge. As soon as the continuous battery charge/discharge current is exceeded, the protection unit needs to monitor the excess current duration and calculate the SOC variation in this period. It then only has to take action if the SOC reaches $0 \%$ or $100 \%$. In this way, peak charge/discharge currents will also be tolerated for specific time periods. The protection unit reaction can be any of the scenarios described for voltage range violation. It should also be noted that in order to achieve the protection for both charge and discharge, the BMS needs to be able to differentiate between charge and discharge by assigning a current sign convention, e.g., positive for discharge and negative for charge.

The operating temperature range for Li-ion batteries which is usually between $-20{ }^{\circ} \mathrm{C}$ and $55{ }^{\circ} \mathrm{C}$ is very likely to be violated in applications such as transportation. In order to circumvent the undesirable effects of temperature range violation, an efficient thermal management subsystem is required. The thermal management subsystem monitors cells and/or pack temperatures and maintains their temperatures within desired ranges. Depending on the BMS complexity and ambient battery temperature, the thermal management system might incorporate passive cooling, active air or liquid cooling, or refrigeration. Another important issue regarding the temperature of Li-ion batteries is a phenomenon called "thermal runaway." Thermal runaway can occur due to ambient conditions, structural defects, or battery abuse. In any case, thermal runaway is usually not detectable by temperature sensor measurements as the internal temperature of li-ion battery cells is significantly higher than their casing temperature. This issue may be prevented by implementing an estimation algorithm capable of monitoring internal cell temperature. Thermal management system design and internal battery temperature estimation are among two future studies that will be conducted on the experimental testbed.

\section{Indication of Battery States}

Li-ion battery states include the battery's operational conditions that affect the performance of the battery and also the systems connected to it. These states include SOC and SOH. SOC shows the amount of charge remaining in the battery compared to a full battery. In other words, it is an indication of the operation scope of the battery-powered device. From an electrochemical point of view, SOC is the ratio of the lithium ion concentration to the maximum lithium ion concentration in the negative electrode (limiting electrode). It is mathematically defined by: 


$$
\operatorname{SOC}(t)=\frac{\operatorname{SOC}\left(t_{0}\right) \times Q_{\text {nom }}-\int_{t_{0}}^{t} I_{t}(\tau) d \tau}{Q_{\text {nom }}}
$$

where $Q_{n o m}$ is the nominal capacity $(\mathrm{A} \cdot \mathrm{h}) ; I_{t}(t)$ is the battery terminal current; $t_{0}$ is the initial time (s); and $t$ is the elapsed time (s). Equation (10) cannot be used in practice to obtain SOC due to issues arising from measurement noise in $I_{t}$ and also the unavailability of $S O C\left(t_{0}\right)$ in different applications. Therefore, since SOC is not measurable, an estimation algorithm is usually required to estimate the SOC using the battery's measurements, i.e., current, voltage, and temperature. Although the majority of SOC estimation algorithms rely on a battery model to acquire SOC, some non-model based methods have also been proposed. Among these types of methods, a combination of battery current integration, using Equation (10), and the voltage translation method is the most common one. The voltage translation method is based on the battery voltage versus SOC relationship and is typically used to calibrate the current integration method. Model-based methods, on the other hand, employ either an electrochemical model or an equivalent-circuit model. As mentioned earlier, [10,11,28-30] are some of the works recently conducted on SOC estimation based on full-order or reduced-order electrochemical models. However, due to the aforementioned implementation simplicity of equivalent-circuit models, there is a large body of literature using equivalent-circuit models to estimate battery SOC. In these works, different battery models are used along with an estimation algorithm such as Extended Kalman Filter [26,39], sliding-mode observers [24,40], adaptive observers [41], and linear parameter varying (LPV) observers [42].

Battery SOH is an indication of battery status compared to a fresh battery. In other words, it captures battery cycle life and aging effects. There is not a universal definition for SOH and different battery parameters are considered as indications of $\mathrm{SOH}$. Among these parameters, battery capacity and internal resistance are the most popular ones. Due to the arbitrary definition of $\mathrm{SOH}$, different authors [40-43] have used different methods and criteria to obtain $\mathrm{SOH}$. The majority of $\mathrm{SOH}$ estimation algorithms employ a parameter identification method such as Kalman filtering [44] or adaptive estimators [45] in order to obtain some battery parameters. In these studies, the changes in parameters such as internal resistance or battery capacity are considered to be the $\mathrm{SOH}$.

At the initial stages of the experimental testbed development, battery state of charge is obtained using the combination of current integration and voltage translational methods, as explained earlier. Although this combination is one of the most-commonly used SOC indication algorithms, the sliding-mode observer introduced in [24] will be used in the future due to this method's intrinsic robustness against model uncertainties. As mentioned earlier, the main focus of this testbed in the future will be to design SOC and SOH algorithms for battery packs. This research area is of utmost importance in real world applications; however, it has not received much attention in the literature.

\section{Summary and Conclusions}

In this paper, the development of an experimental Li-ion battery research testbed was presented. The main purpose of this testbed is to investigate current BMS technologies, determine their weaknesses and strengths, and identify future research paths to improve existing BMS methodologies. After a detailed description of design considerations and system development, battery characterization and 
modeling were studied, and some of the essential functionalities of BMSs were reviewed. These functionalities include: electrical and thermal protection, cell balancing, and battery state indication. The most commonly-used algorithms for each of these subsystems, along with their advantages and disadvantages, were introduced and open research areas in BMS design were reviewed. The need for further research is significant in areas such as thermal modeling, protection, optimal cell balancing, and SOC estimation. Specifically, battery packs require special attention as it is not very trivial to extend cell-level algorithms such as SOC estimation and protection system, to battery packs. In order to address these issues and challenges, the experimental testbed can be configured in three platforms, namely; single cell, cell balancing, and battery pack research platforms. Some initial experimental test results were presented to illustrate the capabilities of the testbed. Future work involves further tests on battery characterization and modeling and developing novel algorithms based on optimal control theory that can address cell balancing issues. Finally, as the main focus of future work, challenges in battery packs including protection and individual cell and pack SOC indication will be addressed. The ultimate goal of the testbed is to provide a platform to facilitate the improvement of existing BMS technologies in order to have more efficient and reliable Li-ion battery systems.

\section{Acknowledgments}

The authors gratefully acknowledge the financial support for this work from the Department of Energy (DE-EE0002012).

\section{Conflicts of Interest}

The authors declare no conflict of interest.

\section{References}

1. Whittingham, M.S. Electrical energy storage and intercalation chemistry. Science 1976, 192, 1126-1127.

2. Oates, K. Lithium-Ion Batteries: Commercialization History and Current History; Foresight Science \& Technology: Providence, RI, USA, 2010.

3. Bazzi, A.M. Electric Machines and Energy Storage Technologies in EVs and HEVs for over a Century. In Proceedings of the IEEE International Electric Machines and Drive Conference, Chicago, IL, USA, 12-15 May 2013; pp. 225-232.

4. Mulder, G.; Omar, N.; Pauwels, S.; Leemans, F.; Verbrugge, B.; Nijs, W.D.; Bossche, P.V.D.; Six, D.; Mierlo, J.V. Enhanced test methods to characterize automotive battery cells. J. Power Sources 2011, 196, 10079-10087.

5. Jiang, M.; Key, B.; Meng, Y.S.; Grey, C.P. Electrochemical and structural study of the layered, "Li-excess" lithium-ion battery electrode material $\mathrm{Li}\left[\mathrm{Li}_{1 / 9} \mathrm{Ni}_{1 / 3} \mathrm{Mn}_{5 / 9}\right] \mathrm{O}_{2}$. Chem. Mater. 2009, 21, 2733-2745.

6. O’Hayre, R.P.; Cha, S.W.; Colella, W.; Prinz, F.B. Fuel Cell Fundamentals, 1st ed.; John Wiley and Sons, Inc.: New York, NY, USA, 2009. 
7. Omar, N.; Daowd, M.; Hegazy, O.; Mulder, G.; Timmermans, J.-M.; Coosemans, T.; Bossche, P.V.D.; Mierlo, J.V. Standardization work for BEV and HEV applications: Critical appraisal of recent traction battery documents. Energies 2012, 5, 138-156.

8. U.S. Department of Energy Vehicle Technologies Program: Battery Test Manual for Power-Assist Hybrid Electric Vehicles; Idaho National Laboratory: Idaho Falls, ID, USA, 2008.

9. Doyle, M.; Fuller, T.F.; Newman, J. Modeling of galvanostatic charge and discharge of the lithium/polymer/insertion cell. J. Electrochem. Soc. 1993, 140, 1526-1533.

10. Smith, K.; Wang, C.-Y. Power and thermal characterization of a lithium-ion battery pack for hybrid-electric vehicles. J. Power Sources 2006, 160, 662-673.

11. Chaturvedi, N.A.; Klein, R.; Christensen, J.; Ahmed, J.; Kojic, A. Algorithms for advanced battery-management systems. Control Syst. Mag. 2010, 30, 49-68.

12. Chen, M.; Rincón-Mora, G.A. Accurate electrical battery model capable of predicting runtime and I-V performance. IEEE Trans. Energy Convers. 2006, 21, 504-511.

13. Hu, X.; Li, S.; Peng, H. A comparative study of equivalent circuit models for Li-ion batteries. J. Power Sources 2012, 198, 359-367.

14. Lu, L.; Han, X.; Li, J.; Hua, J.; Ouyang, M. A review on the key issues for lithium-ion battery management in electric vehicles. J. Power Sources 2013, 226, 272-288.

15. Lithium Battery Failures. Available online: http://www.mpoweruk.com/lithium_failures.htm (accessed on 30 July 2013).

16. Yeow, K.; Teng, H.; Thelliez, M.; Tan, E. Comparative Study on Thermal Behavior of Lithium-Ion Battery Systems with Indirect Air Cooling and Indirect Liquid Cooling. In Proceedings of the ASME/ISCIE International Symposium on Flexible Automation, St. Louis, MO, USA, 18-20 June 2012; pp. 1-7.

17. Andrea, D. Battery Management Systems for Large Lithium-Ion Batteries, 1st ed.; Artech House: Boston, MA, USA, 2010.

18. Li, L. Battery Management System of Lithium Ion Battery in Pure EV. Master's Thesis, Beijing Jiaotong University, Beijing, China, June 2009.

19. Raztec Sensors: Hall Effect Current Sensors and Current Tranducers that Make Ideal Current Shunt and Currect Transformer Replacements. Available online: http://www.raztec.co.nz/ (accessed on 30 July 2013).

20. CAN in Automation (CiA): CAN History. Available online: http://www.can-cia.de/index.php?id=161 (accessed on 30 July 2013).

21. Omar, N.; Daowd, M.; Bossche, P.V.D.; Hegazy, O.; Smekens, J.; Coosemans, T.; Mierlo, J.V. Rechargeable energy storage systems for plug-in hybrid electric vehicles-Assessment of electrical characteristics. Energies 2012, 5, 2952-2988.

22. Electric Motorsport EV Parts. Available online: http://www.electricmotorsport.com/store/ems_ev _parts_batteries_lpf_gbs_20ah.php (accessed on30 July 2013).

23. Doerffel, D.; Sharkh, S.A. A critical review of using the Peukert equation for determining the remaining capacity of lead-acid and lithium-ion batteries. J. Power Sources 2006, 155, 395-400.

24. Lotfi, N.; Landers, R.G. Robust Nonlinear Observer for State of Charge Estimation of Li-ion Batteries. In Proceedings of the 5th Annual Dynamic Systems and Control Conference, Ft. Lauderdale, FL, USA, 17-19 October 2012. 
25. Verbrugge, M.; Tate, E. Adaptive state of charge algorithm for nickel metal hydride batteries including hysteresis phenomena. J. Power Sources 2004, 126, 236-249.

26. He, H.; Xiong, R.; Zhang, X.; Sun, F.; Fan, J. State-of-charge estimation of the lithium-ion battery using an adaptive extended Kalman filter based on an improved Thevenin model. IEEE Trans. Veh. Technol. 2011, 60, 1461-1469.

27. Daowd, M.; Omar, N.; Mierlo, J.V.; Bossche, P.V.D. An extended PNGV battery model for electric and hybrid vehicles. Int. Rev. Electr. Eng. 2011, 6, 1692-1706.

28. Santhanagopalan, S.; White, R.E. Online estimation of the state of the charge of a lithium ion cell. J. Power Sources 2006, 161, 1346-1355.

29. Domenico, D.D.; Fiengo, G.; Stefanopoulou, A. Lithium-Ion Battery State of Charge Estimation with a Kalman Filter Based on an Electrochemical Model. In Proceedings of the IEEE International Conference on Control Applications, San Antonio, TX, USA, 3-5 September 2008; pp. 702-707.

30. Moura, S.J.; Chatruvedi, N.A.; Kristic, M. Adaptive PDE Observer for Battery SOC/SOH Estimation. In Proceedings of the 5th Annual Dynamic Systems and Control Conference, Ft. Lauderdale, FL, USA, 17-19 October 2012.

31. Cao, J.; Schofield, N.; Emadi, A. Battery Balancing Methods: A Comprehensive Review. In Proceedings of the IEEE Vehicle Power and Propulsion Conference, Harbin, China, 3-5 September 2008; pp. 1-6.

32. Daowd, M.; Omar, N.; Bossche, P.V.D.; Mierlo, J.V. Passive and Active Battery Balancing Comparison Based on MATLAB Simulation. In Proceedings of the IEEE Vehicle Power and Propulsion Conference, Chicago, IL, USA, 6-9 September 2011; pp. 1-7.

33. Guo, K.Z.; Bo, Z.C.; Gui, L.R.; Kang, C.S. Comparison and Evaluation of Charge Equalization Technique for Series Connected Batteries. In Proceedings of the IEEE Power Electronics Specialists Conference, Jeju, Korea, 18-22 June 2006; pp. 1-6.

34. Uno, M. Single- and Double-Switch Cell Voltage Equalizers for Series-Connected Lithium-Ion Cells and Supercapacitors. In Energy Storage-Technologies and Applications; InTech: Rijeka, Croatia, 2013; Charter 7, pp. 149-176.

35. Uno, M.; Tanaka, K. Single-switch cell voltage equalizer using multistacked buck-boost converters operating in discontinuous conduction mode for series-connected energy storage cells. IEEE Trans. Veh. Technol. 2011, 60, 3635-3645.

36. Uno, M.; Tanaka, K. Single-switch multioutput charger using voltage multiplier for series-connected lithium-ion battery/supercapacitor equalization. IEEE Trans. Ind. Electron. 2013, 60, 3227-3239.

37. Imtiaz, A.M.; Khan, F.H. Time shared flyback converter based regenerative cell balancing technique for series connected Li-ion battery strings. IEEE Trans. Power Electron. 2013, 28, 5960-5975.

38. Moura, S.J.; Chatruvedi, N.A.; Kristic, M. Constraint Management in Li-Ion Batteries: A Modified Reference Governor Approach. In Proceedings of the American Control Conference, Washington, DC, USA, 17-19 June 2013; pp. 5352-5357.

39. Plett, G.L. Sigma-point Kalman filtering for battery management systems of LiPB-based HEV battery packs: Part 1: Introduction and state estimation. J. Power Sources 2006, 161, 1356-1368.

40. Kim, I.-S. A technique for estimating the state of health of lithium batteries through a dual-sliding-mode observer. IEEE Trans. Power Electron. 2010, 25, 1013-1022. 
41. McIntyre, M.; Burg, T.; Dawson, D.; Xian, B. Adaptive State of Charge (SOC) Estimator for a Battery. In Proceedings of the American Control Conference, Minneapolis, MN, USA, 14-16 June 2006; pp. 5740-5744.

42. Hu, Y.; Yurkovich, S. Battery State of Charge Estimation in Automotive Applications Using LPV Techniques. In Proceedings of the American Control Conference, Baltimore, MD, USA, 30 June-2 July 2010; pp. 5043-5049.

43. Remmliner, J.; Buchholz, M.; Meiler, M.; Bernreuter, P.; Dietmayer, K. State-of-health monitoring of lithium-ion batteries in electric vehicles by on-board internal resistance estimation. J. Power Sources 2011, 196, 5357-5363.

44. Plett, G.L. Extended Kalman filtering for battery management systems of LiPB-based HEV battery packs: Part 3. State and parameter estimation. J. Power Sources 2004, 134, 277-292.

45. Verbrugge, M. Adaptive, multi-parameter battery state estimator with optimized time-weighting factors. J. Appl. Electrochem. 2007, 37, 605-616.

(C) 2013 by the authors; licensee MDPI, Basel, Switzerland. This article is an open access article distributed under the terms and conditions of the Creative Commons Attribution license (http://creativecommons.org/licenses/by/3.0/). 